\title{
ACHIEVEMENT MOTIVATION, PERSONALITY TRAITS AND THEIR RELATION TO GENERAL AND CAREER SELF-EFFICACY
}

\author{
Elena Lisá \\ Faculty of Psychology, Pan-European University (Slovakia)
}

\begin{abstract}
Introduction: We started from Bandura's theory of self-efficacy, the onion model of achievement motivation according to Schuler \& Prochaska, and 5-factor personality theory by Costa \& McCrae. The aim of the study was to analyze the correlation and regression analysis of achievement motivation, personality traits, and general self-efficacy / domain-specific career self-efficacy. We expected the stronger relationship of stable personality characteristics with general self-efficacy than with specific-domain career self-efficacy.

Methods: 713 adult participants (university students and working adults) completed an achievement motivation questionnaire, a five-factor personality theory questionnaire, and a general and career self-efficacy questionnaire.

Results: Regression analysis showed, that confidence in success, dominance, competitiveness, and independence explained $45.7 \%$ of the general self-efficacy score. Confidence in success, independence, goal setting, fearlessness, dominance, internality, and competitiveness explained 38.5\% of career self-efficacy. With the combination of personality and motivational predictors, we have achieved the following results: confidence in success, dominance and five-factor personality traits explained $59.3 \%$ of general self-efficacy. Confidence in success, independence, conscientiousness, extraversion, goal setting, fearlessness, dominance, and competitiveness explained $42.5 \%$ of career self-efficacy.

Conclusion: Confidence in success, dominance, and competitiveness can be seen as general motivational predictors of self-efficacy (general or domain-specific); fearlessness of career efficacy. Achievement motivation is the stronger predictor of the general and career efficacy than personality traits are. Stable traits and achievement motivation dimensions had bigger predictive power when speaking about general self-efficacy than domain-specific career self-efficacy.

Discussion: For further research, we recommend verifying relationships between self-efficacy constructs and some other important personality characteristics, e.g. attachment styles.
\end{abstract}

Keywords: Achievement motivation, traits, general self-efficacy, career self-efficacy.

\section{Self-efficacy}

Self-efficacy refers to the personal beliefs or to an individual's confidence in his own ability to perform effectively specified tasks. It affects behavior and motivation. The self-efficacy theory states that there are four main sources of efficacy expectations: previous performance accomplishments, vicarious experiences, verbal persuasion, and physiological states (Bandura 1977). These sources show the dynamic nature of self-efficacy. Efficacy beliefs influence how people feel, think, motivate themselves, and behave (Bandura, 1993). Bandura stated that beliefs about the nature of ability can make a difference in a group's performance. For example, people who believed that ability has an inherent intellectual nature failed in group problem-solving. They who believed that ability is an acquired skill achieved the group goals more efficiently. They simply managed better by fostering a "highly resilient sense of personal efficacy" (p. 121).

According to motivation Bandura says that self-efficacy beliefs play a key role in the self-regulation of motivation through cognition. He distinguishes three different forms of cognitive motivators: casual attributions, outcome expectancies, and cognized goals. Self-efficacy works with all three forms of cognitive motivators. It causes the difference in intellectual performance between children with the same level of cognitive ability but a different level of self-efficacy. The research in university students' samples proved the meditational role of self-efficacy on achievement motivation and learning strategies (Yusuf, 2011b) and a considerable correlation between self-efficacy and achievement motivation (Yusuf, 2011a).

Self-efficacy theory (Bandura,1982) says that perceived self-efficacy is a major motivational factor that contributes to successful task performance. Research showed that self-efficacy is the most 
important predictor of university student achievement (Bartimote-Aufflick, Bridgeman, Walker, Sharma, \& Smith, 2016). Bandura understands motivation as a cognitive phenomenon and the self-efficacy in the same way. He said: "Expectations of personal efficacy do not operate as dispositional determinants independently of contextual factors." (Bandura, 1977, p. 203). Hence, it is necessary for a subject to identify the circumstance and to determine the required behavior. The dynamic nature of self-efficacy is therefore used for developmental goals in various settings, e.g. schools (Bartimote-Aufflick, et al., 2016). An example of a domain-specific self-efficacy is a also career self efficacy. It is broadly defined as "confidence in one's ability to manage career development and work-related tasks" (O'Brien, 2003, p. 110).

When speaking about achievement and motivation we cannot forget dispositional theories. From that point of view, achievement motivation is a personality variable that has been used to explain individual differences in various contexts. It can be regarded as a complex construct consisting of different layers of dimensions, something as onion. Schuler \& Prochaska (2011) view achievement motivation model as an onion model. Layers of onion are layers of personality: background variables (neuroticism, conscientiousness), theoretical compounds (locus of control, attribution style, self-confidence), peripheral facets (independence, status orientation), core facets (hope of success, goal setting, persistence). Therefore "it is regarded as a general orientation of the person towards the achievement" (p.9).

In spite of the fact, that self-efficacy is the dynamic cognitive construct, research in last years showed that personality traits contribute as antecedents to domain-specific kinds of self-efficacy, e.g. career self-efficacy (Brown \& Cinamon, 2016; Hartman \& Betz, 2007; Bullock-Yowell, Andrews, \& Buzzetta, 2011), computer self-efficacy (Saleem, Beaudry, \& Croteau, 2011), creative self-efficacy (Karwowski, Lebuda, Wisniewska, \& Gralewski, 2013), entrepreneurial self-efficacy (Şahin, Karadağ, $\&$ Tuncer, 2019). These findings are important in light of the integration of trait and social-cognitive perspectives.

\section{Objectives}

We expect a significant relationship between the stable characteristics of personality and self-efficacy constructs. When considering the power of the situation in case of domain-specific self-efficacy constructs, we expect that the relationship between stable personality characteristics (achievement motivation, and personality traits) and generalized efficacy will be stronger than between stable personality characteristics (achievement motivation, and personality traits) and career self-efficacy.

\section{Methods}

Seven hundred and thirteen university students and adults participated in the research. All participants took achievement motivation inventory, 690 of them fulfilled career efficacy questionnaire, 600 five-factor personality inventory, 268 general self-efficacy scale. The participants were collected by the snowball method. The first contact - psychology students collected the data and they received the credits for a research practice course. The data were collected and processed anonymously. Participation in the research was voluntary.

Achievement motivation inventory (LMI; Schuller \& Prochaska, 2011) in the Slovak language contains 170 items in a 7-point Likert format from (1) "Does not apply at all" to (7) "Applies fully to me". The final questionnaire consists from 17 dimensions - Fearlessness, Flexibility, Independence, Preference for Difficult Tasks, Confidence in Success, Dominance, Goal Setting, Eagerness to Learn, Competitiveness, Compensatory Effort, Engagement, Pride in Productivity, Status Orientation, Flow, Internality, Persistence, Self-Control.

Generalized Self-Efficacy Scale (GSES) was confirmed as a cultural independent tool in 25 countries of the world (Luszczynska, Scholz, \& Schwarzer, 2005; Scholz, Gutiérrez-Doña, Sud, \& Schwarzer, 2002). For the research purpose, we used the Slovak version of the GSES (Košč, Heftyová, Schwarzer, \& Jerusalem, 1993). It contains 10 items in a 4-point Likert format from (1) "Not true" to (7) "The truth".

The Career Decision Self-Efficacy scale-Short Form (CDSES; Betz, Klein, \& Taylor in O’Brien, 2003 ) is a self-report, 25-item inventory developed to assess confidence in making career-related decisions and engaging in tasks related to career decision making. A 5-point continuum, ranging from no confidence at all (1) to complete confidence (5) was used. All items were summed to obtain the total score on the CDSES-SF. High scores reflect strong levels of confidence in completing career-related tasks.

NEO the five-factor personality inventory NEO-FFI represents a shortened version of the five-factor personality theory questionnaire (Ruisel \& Halama, 2007) that measures five main personality traits: neuroticism, extraversion, openness to experience, agreeableness, and conscientiousness. The dimensions represent the sum of answers for 12 questions using ratings from 1 to 5 . 
The data were analyzed by JASP 0.11.1.0 (correlation, and regression analysis). The study is part of the research project GA AA 3_5/2020.

\section{Results}

Correlation analysis showed small to large correlation coefficients between self-efficacy, personality traits and achievement motivation dimensions (Table 1).

Five achievement motivation dimensions predict general self-efficacy: dominance, confidence in success, flexibility, competitiveness, and goal setting. The regression model explains $48,3 \%$ of general self-efficacy score variability $(\mathrm{R}=0,695 ; \mathrm{R} 2=0,483 ; \mathrm{F}(17240)=13,192 ; \mathrm{p}<.001)$.

All five personality traits in combination with four dimensions of achievement motivation (dominance, confidence in success, self-control, and competitiveness) significantly predict general self-efficacy. The regression model explains $61,3 \%$ of general self-efficacy score variability $(\mathrm{R}=0,783$; $\mathrm{R} 2=0,613 ; \mathrm{F}(22226)=16,297 ; \mathrm{p}<.001)$.

Nine achievement motivation dimensions (dominance, confidence in success, flexibility, fearlessness, internality, eagerness to learn, preference for difficult tasks, competitiveness, and goal setting) significantly predict career self-efficacy. The regression model explains 39,7 \% of career self-efficacy score variability $(\mathrm{R}=0,630 ; \mathrm{R} 2=0,397 ; \mathrm{F}(17655)=25,380 ; \mathrm{p}<.001)$.

Three traits of personality (extraversion, agreeableness, and conscientiousness) with six achievement motivation dimensions (dominance, engagement, confidence in success, fearlessness, competitiveness, and goal setting) significantly predict career self-efficacy score. The regression model explains 44,4 \% of career self-efficacy score $(\mathrm{R}=0,666 ; \mathrm{R} 2=0,444 ; \mathrm{F}(22537)=19,467$; $\mathrm{p}<.001)$.

\section{Discussion}

Stable traits and achievement motivation dimensions significantly predict both, general and career self-efficacy. They had bigger predictive power when speaking about general self-efficacy than about domain-specific career self-efficacy. Achievement motivation is the stronger predictor of the general and career efficacy than personality traits are. When speaking about the general self-efficacy score, all five personality traits predict the overall score. In comparison with that, only three personality traits predict the domain-specific career self-efficacy score. It agrees with Bandura s (1993) statement, that domain-specific efficacy constructs depend more on the situation. Dominance, confidence in success and competitiveness as the achievement motivation dimensions can be seen as general motivational predictors of self-efficacy, whether general or career. These motivational dimensions of the LMI questionnaire belong to the most stable ones (Prochaska \& Schuler, 2011). Dominance reflects a tendency to exercise power and influence others. Confidence in success reflects a tendency to achieve success even when there are obstacles to overcome. This phenomenon described Bandura (1993) as a key behavioral strategy of highly efficient thinking. Competitiveness expresses the desire to win and be better and faster than others. Dimension fearlessness was included in career self-efficacy predictive models and it was not significant in the general self-efficacy regression model. Fearlessness expresses a lack of fear of failing at difficult tasks, or of being judged by others (Schuler \& Prochaska, 2011).

There are also other studies that showed a significant relationship between self-efficacy and achievement motivation. Small to medium correlation between self-efficacy and achievement motivation was found (Liqin \& Lesen, 2018; Harahsheh, 2017; Jalal, Mansor, \& Arshadi, 2016), but also no significant correlation (Sharma, 2015; Zhang, Zhang, Zhang, Liu, Zhang, Wang, \& Liu, 2015). The relatively strong predictive power in the current study can be caused by the stable nature of LMI achievement motivation dimensions.

Relationships between self-efficacy and achievement motivation were recently examined in the context of various variables, e. g. negligence (Jalal, et al., 2016), self-identity and hope (Liqin, Lesen, 2018). For further research, we recommend verifying relationships between self-efficacy constructs and some other important personality characteristics, e.g. attachment (Klanduchová \& Greškovičová, 2019; Greškovičová \& Hírešová, 2019).

\section{References}

Bandura, A. (1977). Self-efficacy: Toward a unifying theory of behavioral change. Psychological Review $84(2), 191-215$.

Bandura, A. (1982). Self-efficacy mechanisms in human agency. American Psychologist, 37 (2), $122-147$. 
Bandura, A. (1993). Perceived Self-Efficacy in Cognitive Development and Functioning. Educational Psychologist, 28 (2), 117-148.

Bartimote-Aufflick, K., Bridgeman, A., Walker, R., Sharma, M., Smith, L. (2016). The study, evaluation, and improvement of university student self-efficacy. Studies in Higher Education, 41 (11), $1918-1942$.

Brown, D., \& Cinamon, R. G. (2016). Personality traits' effects on self-efficacy and outcome expectations for high school major choice. International Journal for Educational and Vocational Guidance, 16, 343-361.

Bullock-Yowell, E., Andrews, L., \& Buzzetta, M. E. (2011). Explaining career decision-making self efficacy: Personality, cognitions, and cultural mistrust. Career Development Quarterly, 59 (5), $400-411$.

Greškovičová, K., Hírešová, I. (2019). Conference: CER Comparative European Research 2019. London: Sciemcee Publishing, 122-125.

Harahsheh, A. H. (2017). Perceived Self-Efficacy and Its Relationship to Achievement Motivation among Parallel Program Students at Prince Sattam University. International Journal of Psychological Studies, 9 (3), Retrieved 03 23, 2020, from: http://doi.org/10.5539/ijps.v9n3p21.

Hartman, R. O., \& Betz, N. E. (2007). The five-factor model and career self-efficacy: General and domain-specific relationships. Journal of Career Assessment, 15, 145-161.

Jalal, P., K., Mansor, M. S., Arshadi, F. K. (2016). The Relationship between Self-Efficacy, Achievement Motivation and Negligence in Students. International Journal of Humanities and Cultural Studies, $6(3), 1788-1799$.

Karwowski, M., Lebuda, I., Wisniewska, E., Gralewski, J. (2013). Big Five Personality Traits as the Predictors of Creative Self-Efficacy and Creative Personal Identity: Does Gender Matter? Journal of Creative Behavior, 47 (3), 215-232.

Klanduchová, E., Greškovičová, K. (2019). Time perspective and bonding. Conference: CER Comparative European Research 2019. London: Sciemcee Publishing, 118-121.

Košč, M., Heftyová, E., Schwarzer, R., Jerusalem M. (1993). Slovakian Adaptation of the General Self-Efficacy Scale. Retrieved 03 23, 2020, from: http://userpage.fu-berlin.de/ health/slovak.htm

Liqin, L., Lesen, Ch. (2018). The Relationship Between Self-Efficacy and Achievement Motivation in Adolescents: A Moderated Mediating Model of Self-Identity and Hope, Psychology and Behavioral Sciences, 7 (3), 69-76.

Luszczynska, A., Scholz, U., Schwarzer, R. (2005). The general self-efficacy scale: Multicultural validation studies. The Journal of Psychology, 139 (5), 439-457.

O’Brien, K. M. (2003). Measuring career self-efficacy: Promoting confidence and happiness at work. In S. J. Lopez \& C. R. Snyder (Eds.), Positive Psychological Assessment: A Handbook of Models and Measures (109-126). Washington, DC, US: American Psychological Association.

Ruisel, I., \& Halama, P. (2007). NEO-FFI: NEO pätfaktorový osobnostný inventár. Praha: Hogrefe Testcentrum.

Şahin, F., Karadağ, H., Tuncer, B. (2019). Big five personality traits, entrepreneurial self-efficacy and entrepreneurial intention: A configurational approach. International Journal of Entrepreneurial Behavior \& Research, 25 (6), 1188-1211.

Saleem, H., Beaudry, A., Croteau, A. M. (2011). Antecedents of computer self-efficacy: A study of the role of personality traits and gender. Computers in Human Behavior, 27 (5), 1922-1936.

Scholz, U., Gutiérrez-Doña, B., Sud, S., Schwarzer, R. (2002). Is general self-efficacy a universal construct? Psychometric findings from 25 countries. European Journal of Psychological Assessment, 18 (3), 242-251.

Schuler, H., \& Prochaska, M. (2011). Dotazník motivácie k výkonu - LMI. Praha: Hogrefe - Testcentrum.

Sharma, K. (2015). A study of self-efficacy and achievement motivation of prospective teachers in relation to their attitude towards teaching. Scholarly Research Journal for Interdisciplinary Studies, 3 (18), 53-57.

Yusuf, M. (2011a). Investigating relationship between self-efficacy, achievement motivation, and self-regulated learning strategies of undergraduate Students: a study of integrated motivational models. Procedia Social and Behavioral Sciences, 15, 2614-2617.

Yusuf, M. (2011b). The impact of self-efficacy, achievement motivation, and selfregulated learning strategies on students' academic achievement. Procedia Social and Behavioral Sciences, 15, 2623-2626.

Zhang, Z.-J., Zhang, Ch.-L., Zhang, X.-G., Liu, X.-M., Zhang, H., Wang, J., Liu, S. (2015). Relationship between self-efficacy beliefs and achievement motivation in student nurses. Chinese Nursing Research, 2 (2-3), 67-70. 
Table 1. Correlations.

\begin{tabular}{|c|c|c|c|c|c|c|c|c|c|c|c|}
\hline & 1 & 2 & 3 & 4 & 5 & 6 & 7 & 8 & 9 & 10 & 11 \\
\hline 1 CDSES & - & & & & & & & & & & \\
\hline 2 GSES & $0.648^{* * *}$ & - & & & & & & & & & \\
\hline $3 \mathrm{~N}$ & $-0.381^{* * *}$ & $-0.456^{* * *}$ & - & & & & & & & & \\
\hline $4 \mathrm{E}$ & $0.386^{* * *}$ & $0.464^{* * *}$ & $-0.409^{* * *}$ & - & & & & & & & \\
\hline $5 \mathrm{O}$ & $0.162^{* * *}$ & $0.212^{* * *}$ & -0.042 & $0.207^{* * *}$ & - & & & & & & \\
\hline $6 \mathrm{P}$ & -0.004 & $-0.158^{*}$ & $-0.178^{* * *}$ & $0.154^{* * *}$ & $0.100^{*}$ & - & & & & & \\
\hline $7 \mathrm{~S}$ & $0.424^{* * *}$ & $0.456^{* * *}$ & $-0.366^{* * *}$ & $0.298^{* * *}$ & 0.036 & $0.229^{* * *}$ & - & & & & \\
\hline $8 \mathrm{PE}$ & $0.392^{* * *}$ & $0.421^{* * *}$ & $-0.478^{* * *}$ & $0.301^{* * *}$ & 0.003 & 0.045 & $0.531^{* * *}$ & - & & & \\
\hline $9 \mathrm{DO}$ & $0.461^{* * *}$ & $0.548^{* * *}$ & $-0.348^{* * *}$ & $0.475^{* * *}$ & $0.241^{* * *}$ & $-0.214^{* * *}$ & $0.263^{* * *}$ & $0.415^{* * *}$ & - & & \\
\hline $10 \mathrm{EN}$ & $0.248^{* * *}$ & $0.266^{* * *}$ & $-0.126^{* *}$ & $0.180^{* * *}$ & 0.032 & -0.080 & $0.410^{* * *}$ & $0.449^{* * *}$ & $0.396^{* * *}$ & - & \\
\hline $11 \mathrm{CS}$ & $0.514^{* * *}$ & $0.592^{* * *}$ & $-0.452^{* * *}$ & $0.394^{* * *}$ & $0.180^{* * *}$ & 0.007 & $0.427^{* * *}$ & $0.534^{* * *}$ & $0.594^{* * *}$ & $0.409^{* * *}$ & - \\
\hline $12 \mathrm{FX}$ & $0.458^{* * *}$ & $0.493^{* * *}$ & $-0.425^{* * *}$ & $0.460^{* * *}$ & $0.257^{* * *}$ & 0.035 & $0.306^{* * *}$ & $0.447^{* * *}$ & $0.495^{* * *}$ & $0.208^{* * *}$ & $0.559^{* * *}$ \\
\hline $13 \mathrm{FL}$ & $0.219^{* * *}$ & $0.238^{* * *}$ & -0.050 & $0.159^{* * *}$ & $0.213^{* * *}$ & -0.070 & $0.224^{* * *}$ & $0.243^{* * *}$ & $0.345^{* * *}$ & $0.446^{* * *}$ & $0.398^{* * *}$ \\
\hline $14 \mathrm{~F}$ & $0.427^{* * *}$ & $0.423^{* * *}$ & $-0.575^{* * *}$ & $0.280^{* * *}$ & $0.110^{* *}$ & 0.003 & $0.320^{* * *}$ & $0.603^{* * *}$ & $0.377^{* * *}$ & $0.195^{* * *}$ & $0.490^{* * *}$ \\
\hline $15 \mathrm{IN}$ & $0.310^{* * *}$ & $0.180^{* *}$ & $-0.395^{* * *}$ & $0.172^{* * *}$ & $0.150^{* * *}$ & $0.254^{* * *}$ & $0.359^{* * *}$ & $0.441^{* * *}$ & $0.165^{* * *}$ & $0.125^{* * *}$ & $0.285^{* * *}$ \\
\hline $16 \mathrm{CE}$ & $0.115^{* *}$ & 0.084 & $0.121^{* *}$ & -0.026 & 0.012 & 0.008 & $0.256^{* * *}$ & $0.155^{* * *}$ & $0.178^{* * *}$ & $0.394^{* * *}$ & $0.274^{* * *}$ \\
\hline 17 PP & $0.279^{* * *}$ & $0.245^{* * *}$ & -0.064 & $0.194^{* * *}$ & $0.120^{* *}$ & 0.039 & $0.411^{* * *}$ & $0.296^{* * *}$ & $0.404^{* * *}$ & $0.421^{* * *}$ & $0.475^{* * *}$ \\
\hline $18 \mathrm{EL}$ & $0.394^{* * *}$ & $0.301^{* * *}$ & $-0.230^{* * *}$ & $0.209^{* * *}$ & $0.334^{* * *}$ & 0.008 & $0.332^{* * *}$ & $0.349^{* * *}$ & $0.471^{* * *}$ & $0.443^{* * *}$ & $0.519^{* * *}$ \\
\hline 19 PT & $0.392^{* * *}$ & $0.455^{* * *}$ & $-0.380^{* * *}$ & $0.245^{* * *}$ & $0.178^{* * *}$ & -0.051 & $0.371^{* * *}$ & $0.556^{* * *}$ & $0.484^{* * *}$ & $0.482^{* * *}$ & $0.628^{* * *}$ \\
\hline 20 ID & $0.461^{* * *}$ & $0.528^{* * *}$ & $-0.508^{* * *}$ & $0.326^{* * *}$ & $0.167^{* * *}$ & -0.020 & $0.401^{* * *}$ & $0.534^{* * *}$ & $0.531^{* * *}$ & $0.322^{* * *}$ & $0.539^{* * *}$ \\
\hline $21 \mathrm{SC}$ & $0.260^{* * *}$ & $0.167^{* *}$ & $-0.255^{* * *}$ & $0.086^{*}$ & 0.016 & $0.207^{* * *}$ & $0.613^{* * *}$ & $0.543^{* * *}$ & $0.159^{* * *}$ & $0.402^{* * *}$ & $0.307^{* * *}$ \\
\hline $22 \mathrm{OS}$ & $0.226^{* * *}$ & $0.235^{* * *}$ & 0.024 & $0.242^{* * *}$ & $0.117^{* *}$ & $-0.243^{* * *}$ & 0.050 & 0.069 & $0.478^{* * *}$ & $0.245^{* * *}$ & $0.348^{* * *}$ \\
\hline $23 \mathrm{CO}$ & $0.132^{* * *}$ & 0.084 & $0.093^{*}$ & $0.178^{* * *}$ & 0.064 & $-0.313^{* * *}$ & 0.008 & $0.074^{*}$ & $0.456^{* * *}$ & $0.304^{* * *}$ & $0.255^{* * *}$ \\
\hline $24 \mathrm{GS}$ & $0.407^{* * *}$ & $0.382^{* * *}$ & $-0.157^{* * *}$ & $0.264^{* * *}$ & $0.226^{* * *}$ & -0.037 & $0.328^{* * *}$ & $0.282^{* * *}$ & $0.467^{* * *}$ & $0.426^{* * *}$ & $0.492^{* * *}$ \\
\hline
\end{tabular}

Table 1. Correlations - continue.

\begin{tabular}{|c|c|c|c|c|c|c|c|c|c|c|c|c|}
\hline & 12 & 13 & 14 & 15 & 16 & 17 & 18 & 19 & 20 & 21 & 22 & 23 \\
\hline $12 \mathrm{FX}$ & - & & & & & & & & & & & \\
\hline $13 \mathrm{FL}$ & $0.320^{* * *}$ & - & & & & & & & & & & \\
\hline $14 \mathrm{~F}$ & $0.539^{* * *}$ & 0.044 & - & & & & & & & & & \\
\hline $15 \mathrm{IN}$ & $0.351^{* * *}$ & $0.124^{* * *}$ & $0.476^{* * *}$ & - & & & & & & & & \\
\hline $16 \mathrm{CE}$ & 0.057 & $0.373^{* * *}$ & $-0.218^{* * *}$ & -0.010 & - & & & & & & & \\
\hline 17 PP & $0.319^{* * *}$ & $0.593^{* * *}$ & -0.006 & $0.186^{* * *}$ & $0.578^{* * *}$ & - & & & & & & \\
\hline $18 \mathrm{EL}$ & $0.471^{* * *}$ & $0.391^{* * *}$ & $0.297^{* * *}$ & $0.217^{* * *}$ & $0.287^{* * *}$ & $0.408^{* * *}$ & - & & & & & \\
\hline $19 \mathrm{PT}$ & $0.602^{* * *}$ & $0.491^{* * *}$ & $0.537^{* * *}$ & $0.296^{* * *}$ & $0.193^{* * *}$ & $0.349^{* * *}$ & $0.547^{* * *}$ & - & & & & \\
\hline 20 ID & $0.566^{* * *}$ & $0.283^{* * *}$ & $0.626^{* * *}$ & $0.416^{* * *}$ & 0.007 & $0.260^{* * *}$ & $0.409^{* * *}$ & $0.584^{* * *}$ & - & & & \\
\hline $21 \mathrm{SC}$ & $0.198^{* * *}$ & $0.131^{* * *}$ & $0.318^{* * *}$ & $0.398^{* * *}$ & $0.274^{* * *}$ & $0.283^{* * *}$ & $0.267^{* * *}$ & $0.313^{* * *}$ & $0.298^{* * *}$ & - & & \\
\hline $22 \mathrm{OS}$ & $0.249^{* * *}$ & $0.344^{* * *}$ & -0.059 & $-0.077^{*}$ & $0.372^{* * *}$ & $0.527^{* * *}$ & $0.345^{* * *}$ & $0.209^{* * *}$ & $0.129^{* * *}$ & -0.012 & - & \\
\hline $23 \mathrm{CO}$ & $0.142^{* * *}$ & $0.384^{* * *}$ & -0.068 & $-0.098^{* *}$ & $0.373^{* * *}$ & $0.445^{* * *}$ & $0.287^{* * *}$ & $0.221^{* * *}$ & $0.099^{* *}$ & -0.018 & $0.666^{* * *}$ & - \\
\hline $24 \mathrm{GS}$ & $0.451^{* * *}$ & $0.406^{* * *}$ & $0.201^{* * *}$ & $0.182^{* * *}$ & $0.361^{* * *}$ & $0.517^{* * *}$ & $0.547^{* * *}$ & $0.475^{* * *}$ & $0.379^{* * *}$ & $0.232^{* * *}$ & $0.578^{* * *}$ & $0.445^{* * *}$ \\
\hline
\end{tabular}

$* \mathrm{p}<.05, * * \mathrm{p}<.01, * * * \mathrm{p}<.001$

CDSES = career self-efficacy; GSES $=$ general self-efficacy; $\mathrm{N}=$ neuroticism; $\mathrm{E}=$ extraversion; $\mathrm{O}=$ openness to experience; $\mathrm{A}=$ agreeableness; $\mathrm{C}=$ conscientiousness; $\mathrm{F}=$ fearlessness; $\mathrm{FX}=$ Flexibility; ID = Independence; PT $=$ Preference for Difficult Tasks; CS = Confidence in Success; DO = Dominance; GS = Goal Setting; $\mathrm{EL}=$ Eagerness to Learn; $\mathrm{CO}=$ Competitiveness; $\mathrm{CE}=$ Compensatory Effort; $\mathrm{EN}=$ Engagement; $\mathrm{PP}=$ Pride in Productivity; $\mathrm{OS}=$ Status Orientation; FL = Flow; IN = Internality; $\mathrm{PE}=$ Persistence; $\mathrm{SC}=$ Self-Control. 